\title{
Exploring perceptions of health caregivers on the causes of caregivers' occupational burnout in institutes of children with cerebral palsy: A qualitative study
}

\author{
Abbass Dehghan ${ }^{1}$, Seyed Ali Hosseini ${ }^{2}$, Mehdi Rassfiani ${ }^{3}$ Hamid Dalvand ${ }^{4}$
}

${ }^{1}$ Ph.D. Student of Occupational Therapy, Department of Occupational Therapy, University of Social Welfare \& Rehabilitation Sciences, Tehran, Iran

${ }^{2}$ Ph.D. of Occupational Therapy, Professor, Social Determinants of Health Research Center and Occupational Therapy Department. University of Social Welfare and Rehabilitation Sciences. Tehran, Iran

${ }^{3}$ Ph.D. of Occupational Therapy, Associate Professor, Department of Occupational Therapy, University of Social Welfare \& Rehabilitation Sciences, Tehran, Iran

${ }^{4}$ Ph.D. Of Occupational Therapy, Assistant Professor, Department of Occupational Therapy, Arak University of Medical Sciences, Arak, Iran.

\section{Type of article: Original}

\begin{abstract}
Background: Providing care for children with cerebral palsy (CP) is hard, energy-consuming, and long-term. Consequently, occupational burnout is highly probable for caregivers.

Objective: This study aimed to explore the perception of health caregivers regarding the causes of caregivers' occupational burnout in institutes of children with CP.

Methods: This qualitative study was conducted using content analysis methodology during an eight-month period in 2016. Nine caregivers, two managers, and one physiotherapist participated in the study. Purposive sampling method was used to select participants. In depth, semi-structure interviews were used to gather the data. All interviews were conducted at their workplace, in Tehran, Iran. The interviews were recorded, transcribed verbatim, and overviewed. Constant comparative analyses were used to analyze the interviews.

Results: The results were categorized into three main categories and nine sub-categories. The main categories were as follows: care-related stress, nature of caring occupation, and organizational demands and resources.

Conclusion: Results of this study showed that several factors are involved in creating burnout among caregivers. The exploration of these factors may help us in designing appropriate interventions for caregivers to correctly implement caring activities so that they less suffer from care-related pressures and also become able to allocate some time for their own activities of interest and for recreational, social, and family activities.

Keywords: Caregivers, Cerebral Palsy, Burnout, Qualitative Research
\end{abstract}

\section{Introduction}

Occupational burnout and its aetiology and symptoms have increasingly drawn attention over the recent years. Constant stress is the main reason for occupational burnout (1). The stress is generated when there is an imbalance between needs and demands of occupation and personal capabilities to meet such expectations (2). In fact, occupational burnout is a prolonged response to chronic emotional and interpersonal stressful factors and situations (3). People who work in occupations like nursing, medicine, occupational therapy, social work, teaching, and caregiving of children are highly prone to occupational burnout (4). The incidence of burnout among medical, nursing staff and caregivers was reported to be up $45-56 \%(2,5-7)$. The reason is that these people are engaged in constant and compassionate caring for individuals with severe physical, intellectual, and emotional tangles $(3,4)$. Occupational burnout can lead to detrimental ramifications for the person, their family, organization, and society at large if it continues unnoticed (8). Lack of sleep, restlessness, regular job absence, depression, psychosomatic

\section{Corresponding author:}

Professor Dr. Seyed Ali Hosseini, University of Social Welfare \& Rehabilitation Sciences, Tehran, Iran.

Tel: +98.2122180037, Email: alihosse@gmail.com

Received: November 24, 2016, Accepted: March 05, 2017, Published: June 2017

iThenticate screening: March 04, 2017, English editing: April 12, 2017, Quality control: May 14, 2017

(C) 2017 The Authors. This is an open access article under the terms of the Creative Commons Attribution-NonCommercialNoDerivs License, which permits use and distribution in any medium, provided the original work is properly cited, the use is non-commercial and no modifications or adaptations are made. 
complaints, efficiency reduction, desertion, and finally defects in quality of provided care are among the main ramifications of burnout (9-12). For the first time, Freudenberg defined occupational burnout to explain dwindling of stamina and energy in tedious and stressful jobs (12). According to Maslach and Jackson, occupational burnout is a multidimensional structure consisting of three interrelated factors of emotional exhaustion, depersonalization, and diminished personal accomplishment that can occur among individuals who do people-work of some kind (13). Among these individuals are the caregivers of children with cerebral palsy (CP). CP is the main reason for physical disability among children (14) that is caused by non-progressive damage to the brain during embryonic and neonatal periods and can lead to motor impairments and activity limitations (15). The incidence of CP has been reported to be 2 to 2.6 cases per 1000 live births in Iran (16). Although motor impairments are of defining features of CP, there are many other secondary defects associated with it, namely spasticity and numerous communicational, auditory, visual, cognitive, behavioral, and emotional problems (17). Children with CP face remarkable limitations in their Activities of Daily Living (ADL) like eating, feeding, grooming, dressing, bathing, and movement (18). These limitations lead to a need for long-term care that is beyond normal care needed for normal developing children at any age (19). Caring for children is of usual and prime parenting duties, but some children, due to some specific reasons, need to be cared for in institutes (20). In long term care institutions, caregivers provide an estimated $60 \%-70 \%$ basic resident care such as assisting in all ADL (21). The negative consequences of caregiving have shown in several studies. In a study conducted in Taiwan, Lin and colleagues showed that caregivers working in institutes for children with physical and intellectual disabilities experience higher rates of burnout than other clerks (10). Elizabeth et al. also showed that in most symptoms (e.g. cognitive, mental, and behavioral) in cerebrovascular accidents (CVA), patients were linked with burnout among caregivers. Also, young female caregivers with weaker levels of physical health were at higher risk of burnout (22). Also in another study, Demirhan and colleagues reported similar results in the mothers of children with cerebral palsy (23). In regards to the high incidence of occupational burnout, particularly in Iran, and its negative consequences such as higher medical costs, losses, and imposition of financial burdens on caregivers, families and society, exploration of the effective factors can help us in designing appropriate interventions for caregivers to correctly implement caring activities. Therefore, this study aimed to explore the perceptions of the health caregivers regarding causes of caregivers' occupational burnout in institutes of children with CP.

\section{Material and Methods}

\subsection{Design}

This qualitative study was conducted to explore the perceptions that the health caregivers have about causes of caregivers' occupational burnout in institutes of children with CP, using a conventional qualitative content analysis method. Following review of participant's experiences, codes were summarized, and compared based on differences and similarities, and sorted into sub-categories and main categories (24).

\subsection{Participants}

Participants were as follows; 9 caregivers, 2 managers, and 1 physiotherapist, all with a history of working with children with CP. To be exact, the participants were selected from institutes supervised by Tehran's Behzisti Welfare Organization and they had at least 6 years of experience of working with such children. Table 1 illustrates the demographic features of participants.

\subsection{Data Collection}

The data were collected via in-depth, semi-structured interviews. The interviews were carried out by the first author (AD) between March 2016 and October 2016 in Tehran, Iran. Having an introduction letter from the University of Social Welfare and Rehabilitation Sciences (USWR) and by referring to centers supervised by Tehran's Behzisti Welfare Organization, participants who met the criteria were chosen. Then, study objectives, data gathering method, and their right to withdraw from participation at any stage they desired were plainly explained, and a consent form was obtained from participants. Required data were gathered through in-depth, semi-structured interviews conducted at each participant's workplace. Samples of interview questions are illustrated in Table 2. Each Interview began with an open-ended question of; "Would you please describe a typical day of your job at the center? Could you tell me exactly what it is that you do for the children here?" The probe questions were asked according to the answers provided for the preceding question. All interviews were tape recorded completely and were transcribed verbatim. The duration of the interviews were between 20 to 45 minutes depending on the interest of the participants in explaining their own experiences. Purposive sampling was used to choose the participants and continued until data saturation. 


\subsection{Data Analysis}

All interviews were carried out in Persian, which was the native language of both the interviewer and interviewees, and other co-authors checked the English version of the translation, coding and the coherence of the categories. The final English version was checked by a native English speaker for the clarity of the language used. Graneheim conventional content analysis was used to analyze the data. After tape recording the interviews, they were immediately transcribed verbatim. To a general understanding of interviews, obtained data were read over and over. Then, data were analyzed using constant comparative analysis method. To be precise, the data were respectively categorized into meaning units, condensed meaning units, labelled as codes, sub-categories, and main categories. Meaning units were summarized to reduce their long wording into a condensed meaning unit while preserving their very gist. Coding was also conducted following a similar reason of briefing. After coding, the codes were categorized and the main extracted concepts and meanings were interpreted as main categories (24).

\subsection{Rigor}

The conformability and credibility of the data were established in three main ways: (i) participant's revision, (ii) prolonged engagement with the data and the emerging codes and categorizations, and (iii) co-authors' validation of the coding and categorizations. Participants were contacted after the analysis and were given a full transcript of their coded interviews with a summary of the emergent themes to determine whether the codes and themes were true to their point of view (member check). As a further validity check, the Persian-speaking co-authors validated the emerging coding and categorizations by reading the transcripts and the suggested coding. Finally, all the authors checked an English version of the coding and the coherence of the categories. The analysis steps and the decisions made in order to save the audit were documented for other researchers to perform the steps of the research in future studies (25).

\subsection{Ethical Considerations}

Ethical issues were observed through the following measures: Obtaining an informed consent form, anonymity of participants, confidentiality of data, and withdrawal right at any stage of study. Interviews were also set according to the time the participants deemed appropriate. This study was part of a $\mathrm{PhD}$ thesis and was approved by Research Ethics Committee of USWR (Ref: IR.USWR.REC.1394.175).

Table 1. Demographic features of participants

\begin{tabular}{|l|l|l|l|l|l|l|}
\hline $\begin{array}{l}\text { Participant } \\
\text { no. }\end{array}$ & $\begin{array}{l}\text { Age } \\
\text { (year) }\end{array}$ & Education & $\begin{array}{l}\text { Marital } \\
\text { status }\end{array}$ & $\begin{array}{l}\text { Work Experience } \\
\text { (year) }\end{array}$ & Occupation & $\begin{array}{l}\text { Number of } \\
\text { children under care }\end{array}$ \\
\hline 1 & 34 & Guidance school & Married & 7 & Caregiver & 13 \\
\hline 2 & 39 & Elementary school & Divorced & 19 & Caregiver & 12 \\
\hline 3 & 35 & Diploma & Single & 8 & Caregiver & 14 \\
\hline 4 & 43 & Bachelor & Married & 12 & Physiotherapist & ---- \\
\hline 5 & 41 & Elementary school & Married & 26 & Caregiver & 11 \\
\hline 6 & 47 & Bachelor & Married & 15 & Manager & ---- \\
\hline 7 & 40 & Diploma & Married & 7 & Caregiver & 12 \\
\hline 8 & 45 & Elementary school & Married & 6 & Caregiver & 13 \\
\hline 9 & 42 & Masters & Married & 12 & Manager & ---- \\
\hline 10 & 44 & Elementary school & Married & 19 & Caregiver & 13 \\
\hline 11 & 49 & Elementary school & Married & 12 & Caregiver & 10 \\
\hline 12 & 56 & Elementary school & Married & 32 & Caregiver & 15 \\
\hline
\end{tabular}

Table 2. A sample of interview questions

\begin{tabular}{|l|l|}
\hline Question no. & Questions \\
\hline 1 & Could you please describe a day of your job at the centre \\
\hline 2 & Could you inform me of what you do for children here? \\
\hline 3 & What effects has caring for children with CP had on your health? \\
\hline 4 & Did you receive any training about caring for children with CP? \\
\hline 5 & What effects has caring for children with CP had on your life? \\
\hline
\end{tabular}




\section{Results}

Twelve people took part in this study; participants included nine caregivers, two managers, and one physiotherapist with an age range of 34 to 56 (average age: 42.9 years). The participants had at least six years of experience of working with children with CP (Table 1). Caregivers of children with CP described their own experiences and perceptions with these children. Categories were derived from the data that reflected common aspects of the experiences of occupational burnout among caregivers working in institutes for children with $\mathrm{CP}$ in an Iranian context. The analysis resulted in three main categories including: 1) Care-related stress 2) Nature of caring jobs 3) Organizational demands and resources (Table 3).

Table 3. Main categories and sub-categories

\begin{tabular}{|l|l|}
\hline Main categories & Sub-categories \\
\hline Care-related stress & Physical stress \\
\cline { 2 - 2 } & Intellectual stress \\
\cline { 2 - 2 } & Social stress \\
\hline \multirow{4}{*}{ Nature of caring jobs } & High workload \\
\cline { 2 - 2 } & Hardship of caring \\
\cline { 2 - 2 } & Routine of caring jobs \\
\hline Organizational demands and resources & Lack of human resources \\
\cline { 2 - 2 } & Lack of salary and benefits \\
\cline { 2 - 2 } & Educational and training shortcomings. \\
\hline
\end{tabular}

\subsection{Care-related stress}

According to the participants, caring for these children is time-consuming, energy-intensive and long-term, and evokes mental and emotional burden. Stress and pressures of caring have a negative impact on caregivers' physical and mental health as well social activities. These main categories consisted of three sub-categories of: physical stress, intellectual stress, and social stress.

\subsubsection{Physical stress}

As one of the main sub-categories of care-related stress, most of the participants stated that because of long years of working in institutes for children with CP, they have suffered from several physical problems. Musculoskeletal pains especially in places like back, shoulders, feet, and neck are the most prevalent ones. For example, one of the caregivers (participant No. 2) put it like this: “... Many of us complain about lumbago, complain about sore feet. When we get home at night, we are just physically dead. No stamina for our lives ..." Talking about experience of musculoskeletal pains over their years of service, one caregiver (participant No. 12) stated:“... Normally after some years of working, you will experience sore feet and hands, lumbago, and neck pain. I myself have been suffering from lumbar disc and knee arthritis, but as I am in need of the money I have to continue working ..."

\subsubsection{Intellectual stress}

All participants in this study point to this sub-category as a major source of stress. Due to increasing levels of carerelated strains and pressures and also long consecutive years of working in institutes, people who work in institutes for children with CP suffer from several intellectual problems. These problems can have negative effects on their Quality of Life (QOL). One of the managers (participant No. 9) described the issue in this way: “... Most colleagues who work at such centers for 2 or 3 years do suffer from depression. Many mothers see these children as just like their own children, so when they become sick or die, they become upset ..." Another participant (participant No. 4) who was taking care of 13 children with CP described their experience as follows: “... Just like our children, like children that we have at our homes. For example, if they get sick how bad the mother will feel, how bad the father will feel, they give us just as similar emotions. If they get sick, we really feel bad. If, God forbid, they die, we really weep for them as we have emotional attachment to them ..."

\subsubsection{Social stress}

Most caregivers stated that lack of caregivers and their regular work shifts impose real hurdles into their social and recreational life. For example, one of the participants (participant's No. 10) stated that: “... Going to parties is almost non-existent in our life. We can only afford to have a trip annually. All our problems get back to lack of workforce. As there is a lack of workforce here, we have to take a few days off ..." 


\subsection{Nature of caring occupations}

Nature of caring occupations (activities oriented toward taking care of one's own body), considered by participants as one of the causes in development caregivers' occupational burnout, have three sub-categories, including high workload, routines of caring activities, and hardship of caring.

\subsubsection{High workload}

The high workload of a "Madaryar" (A Persian word for a type of caregiver, literally meaning "quasi-mother") was reported as a problem in the present study. A high workload could have a negative impact on the quality of the care that they provided. One of the participants (participant No. 3) stated that:“... A Madaryar has 15 children under care, she bathes them, dresses them, goes to hospital, trims their nails, regularly visits them, washes their beds, and cleans everything and everywhere at Nowruz (The beginning of New Year in the Persian calendar). This is the Madaryar, she is a jack of all trades! ..." Another (participant No. 10) described their experience as the following:" “... One thing that we have been challenged with over the last 4 to 5 years is the high workload of our job, something that we have no control over. For example, a Madaryar should take care of 20 children, so her workload is really high. It all, eventually, leads to a compromise in quality of care ...".

\subsubsection{Hardship of caring}

Caring for someone with a disability can be tiring, both physically and emotionally. One of the participants (participant No. 2) explained that: “... Our job is really physically strenuous. You have to always change your position in order to dress them, feed them, and bathe them. Also, you have to be with them during their physiotherapy ..." When talking about hardship of their job, another caregiver (participant No. 5) stated that:"“... Working is really tough here. Working is hard physically and mentally, but there is no fringe benefit for this hardship ..."

\subsubsection{Routine of caring jobs}

Participants stated that repetitiousness and constancy of their caring duties were of the main challenges for working at centers for children with CP. In this regard, one participant (participant No. 6) stated that: "... We deal with patients who are always here. We are always seeing, caring, and feeding these same children ...".

\subsection{Organizational demands and resources}

Experiences of participants indicated that one of the causes that can have an important role in the development of burnout is organizational demands and resources. The prolonged experience of low resources and high demands lead to an erosion of other resources such as energy, identification, and perceived efficacy, which is the burnout process (26). This main category includes concepts such as: Lack of human resources, Lack of fringe benefits, and educational shortcomings.

\subsubsection{Lack of human resources}

Lack of a Madaryar is one of the main challenges in centres for disabled children. Some of the major damages to these children, in fact, stem from such a lack. Even, a decrease in quality of care is sometimes due to the lack of Madaryars. One of the managers (participant No. 6) described it in this way:“... We have very few personnel. I was looking at the schedule of our Madaryar and she rarely stays at her home to care for her family. She is here either to bathe children, or as overtime, or to do her own work shift. We hugely lack enough workforce ..."

On lack of workforce and its effect on the health of children and also on care quality, one of the caregivers (participant No. 5) stated that:“... Lack of workforce is really an influential issue here. When I work here for 12 hours, I have no efficiency to work for another 12 hours. It really affects children. This lack of workforce has been a challenge for years ..."

\subsubsection{Lack of salary and benefits}

Participants believed that there was an imbalance between their workload and allocated salary and benefits. Caregivers expect their job should at least be listed among difficult jobs. This way they would be able to enjoy the fringe benefits. Accordingly, one of the caregivers (participant No. 12) said the following:"... Our salaries are really meagre. We have no fringe benefits. We are worn-out at all levels. No one listens to or cares about us. We even complained to the Ministry of Labour, but they told us that we are not included into the difficult jobs category. Why? Because our job is not listed so ...”. Another (participant No. 8) said something similar:“... Unfortunately, our salary is nothing to our workload. The difficulty of our job is not considered. Even worse, our job is not listed as a difficult job in labour related rules ..."

\subsubsection{Educational shortcomings}

Most caregivers stated that they never took part in relevant training and educational courses. In fact, they learned the job in 2 or 3 weeks by observing experienced Madaryars. Lack of awareness about particularities of caring for children with $\mathrm{CP}$ can lead to serious damages to those children. One of the caregivers (participant 6) described the issue in the following way:“... Early in my career, when I was so young, I received no training and became burned- 
out very soon. I suffer from lumbar disc and neck disc now. These are the problems that I have got ..." Another caregiver (Participant No 5) told us that: “... All these new caregivers had seen no training or education. If someone like me receives proper training early on, they will be accustomed to that and continue working accordingly. There is no training now. They let Madaryars work and become burnt-out ...”.

\section{Discussion}

Findings of the present study, as the first qualitative study about burnout among caregivers working in institutes for children with $\mathrm{CP}$, showed that care-related stress, nature of caring jobs, and organizational demands and resources play important roles in incidences of burnout among caregivers at those institutes. According to experiences of the participants, care related stress such as physical, intellectual and social stress were the main reasons of burnout among caregivers in the present study. The participants stated that caring for children with C.P leads to a sense of depression, poor perception of physical health, and tiredness or exhaustion in caregivers. This result is similar to some previous studies. The study results of Horng et al. showed that the prevalence of work-related musculoskeletal disorders was high among child care workers, and it might have a negative impact on absence-days. Results showed that low back pain $(57.0 \%)$, shoulder pain $(54.7 \%)$ and neck pain $(45.3 \%)$ were the most common musculoskeletal disorders (27). In a study by Takai et al. about association between occupational burnout and depression and quality of life among home caregivers who provided care for people with dementia, a significant relationship was seen between burnout and environmental, social, mental and physical quality of caregivers' life (3). Basaran et al., in a cross-sectional study, showed that caregivers in CP group had poor QOL, worse mental health, and higher burnout levels compared to controls (28). The nature of caring jobs was also an important factor in creation of occupational burnout according to participants' reports. According to job demands-resources model of burnout, job demands like high workload, time limit, work shifts, direct contact with clients, and inapproperiate working environment are of the main reasons for emotional burnout or fatigue among caregivers (29). A high workload will increase the chance of energy and stamina dwindling and emotional burnout. In this regard, Vassos \& Nankervis reported that factors such as large workload, work huors, and low job status are associated with higher levels of burnout in disability support workers' (DSW) pupolation (30). In another study, Chappell \& Novak considered a decrease or change in the workload and provided reward on a job as main factors in alleviating burnout and perceived job pressure (25). According to the majority of participants, organizational demands and resources such as lack of human resources was another important cause in development of burnout. Lack of balance and coordination between workload and manpower caused stress and pressure on the caregivers due to a high number of the children and lack of sufficient manpower. Lack of work-force is a global issue, and all countries are grappling with it in some way. This lack of human resources has hurdled the efforts to provide health related services for children living in those institutes. Attempts to compensate such a lack with overtime activities have kept caregivers away from their families for longer hours and, consequently, dissatisfactory reductions in family members and caregivers' QOL. Salary and benefits are ways and means of life that can secure higher QOL for all family members. Apart from that, salary and benefits are great motivational factors in work. Therefore, not only does a proper level of salary that is proportional to quantity and quality of tasks and performance lead to higher motivation, but it can also increase caregivers' satisfaction. Study results of Anderson suggested that a low wage predicts job dissatisfaction and high turnover rates in residential care aids (31). Decker et al. considered inadequate salary and stressful working conditions as primary cases of burnout in child care workers (12). Harrington et al. associated higher rates of desertion among nurses with high workload, low salary and fringes, and job hardship (32). Educational and training shortcomings were of other organizational demands and resources in the present study. The inexperienced caregivers, especially those who did not have enough training early in their career, lack necessary capabilities and strategies to cope with occupational stresses. Caregivers' awareness about ergonomic principles in caring for children can lead to less musculoskeletal pains. The positive effects of caregivers' training have been shown in different studies. For example, Bilgin and Gozum found that participation in a nursing education programme reduced the level of burnout experienced by mothers who have an intellectually disabled child (33). In another study, Dorota showed that teaching participants how to manage their work environment better could help them in changing their perception of stressful job characteristics, reducing emotional exhaustion and somatic complaints (34). This study had several limitations, lack of access to male caregivers, lack of interest among occupational therapists to take part, Madaryas' reluctance to participate, time limits, and interview interruptions due to care demands. Therefore, it is suggested that there should be more research on caregivers' burnout in future, in which male and female participants do take part. Also, future research should consider social, economic, cultural, and contextual differences in development of studies. 


\section{Conclusions}

Results of this study, as the first research in an Iranian context, revealed that different causes may facilitate occupational burnout in caregivers of children with CP in institutes. Identification of these reasons can lead to betterment of managers' knowledge and, consequently, adoption of more proper organizational planning and policies to increase the quality of caring services at care centers. Also, development and the designing of continuous training programs to manage occupational stresses can reduce stress levels and burnout among caregivers.

\section{Acknowledgments:}

This study is part of a general research of the first author's Ph.D. thesis. The authors gratefully acknowledge all managers, caregivers, clinicians, and also the Occupational Therapy Department at USWR, Tehran (Iran) for their kind help and support. The study received no grant from any government or nongovernment institution.

\section{Conflict of Interest:}

There is no conflict of interest to be declared.

\section{Authors' contributions:}

All authors contributed to this project and article equally. All authors read and approved the final manuscript.

\section{References:}

1) Billeter - Koponen S, Freden L. Long - term stress, burnout and patient - nurse relations: qualitative interview study about nurses' experiences. Scand J Caring Sci. 2005; 19(1): 20-7. doi: 10.1111/j.14716712.2005.00318.x. PMID: 15737161.

2) Merlani P, Verdon M, Businger A, Domenighetti G, Pargger H, Ricou B. Burnout in ICU caregivers: a multicenter study of factors associated to centers. Am J Respir Crit Care Med. 2011; 184(10): 1140-6. doi: 10.1164/rccm.201101-0068OC. PMID: 21852543.

3) Takai M, Takahashi M, Iwamitsu Y, Ando N, Okazaki S, Nakajima K, et al. The experience of burnout among home caregivers of patients with dementia: Relations to depression and quality of life. Arch Gerontol Geriatr. 2009; 49(1): e1-5. doi: 10.1016/j.archger.2008.07.002. PMID: 18703239.

4) Rogers JC, Dodson SC. Burnout in occupational therapists. Am J Occup Ther. 1988; 42(12): 787-92. doi: 10.5014/ajot.42.12.787. PMID: 3223504.

5) Penson RT, Dignan FL, Canellos GP, Picard CL, Lynch TJ Jr. Burnout: caring for the caregivers. Oncologist. 2000; 5(5): 425-34. doi: 10.1634/theoncologist.5-6-531-a. PMID: 11040279.

6) Kanai - Pak M, Aiken LH, Sloane DM, Poghosyan L. Poor work environments and nurse inexperience are associated with burnout, job dissatisfaction and quality deficits in Japanese hospitals. J Clin Nurs. 2008; 17(24): 3324-9. doi: 10.1111/j.1365-2702.2008.02639.x. PMID: 19146591, PMCID: PMC2632807.

7) Zahiri M, Mahboubi M, Mohammadi M, Khodadadi A, Mousavi H, Jalali A. Burnout among nurses working in surgery and internal wards at selected hospitals of Ahvaz. Tech J Engin App Sci. 2014; 4: 7984.

8) Hellesøy O, Grønhaug K, Kvitastein O. Burnout: conceptual issues and empirical findings from a new research setting. Scandinavian journal of management. 2000; 16(3): 233-47. doi: 10.1016/S09565221(99)00028-7.

9) Khodadadi A, Ravari A, Sayadi A, Khodadadi H, Jafarinaveh H. Occupational burnout assessment among nurses working in Iranian hospital of Ali-ebn Abitaleb, Rafsanjan-Iran. Journal of Occupational Health and Epidemiology. 2012; 1(2): 103-10.

10) Lin LP, Lin JD. Job burnout amongst the institutional caregivers working with individuals with intellectual and developmental disabilities: Utilization of the Chinese version of the Copenhagen Burnout Inventory survey. Res Autism Spectr Disord. 2013; 7(6): 777-84. doi: 10.1016/j.rasd.2013.03.004.

11) Poncet MC, Toullic P, Papazian L, Kentish-Barnes N, Timsit JF, Pochard F, et al. Burnout syndrome in critical care nursing staff. Am J Respir Crit Care Med. 2007; 175(7): 698-704. doi: 10.1164/rccm.2006068060C. PMID: 17110646.

12) Decker JT, Bailey TL, Westergaard N. Burnout among childcare workers. Residential Treatment for Children \& Youth. 2002; 19(4): 61-77. doi: 10.1300/J007v19n04_04.

13) Maslach C. Burnout: The cost of caring. ISHK; 1982.

14) Krägeloh-Mann I, Cans C. Cerebral palsy update. Brain Dev. 2009; 31(7): 537-44. doi: 10.1016/j.braindev.2009.03.009. PMID: 19386453. 
15) Bax M, Goldstein M, Rosenbaum P, Leviton A, Paneth N, Dan B, et al. Proposed definition and classification of cerebral palsy, April 2005. Dev Med Child Neurol. 2005; 47(8): 571-6. doi: 10.1017/S001216220500112X. PMID: 16108461.

16) Joghataei MT, Mohammad K, Rahgozar M, Siadati S. Prevalence of some paralysis and limb amputation disabilities in Iran national epidemiological survey. Journal of Rehabilitation. 2002; 3(8-9): 7-16.

17) Burkhard A. A different life: caring for an adolescent or young adult with severe cerebral palsy. J Pediatr Nurs. 2013; 28(4): 357-63. doi: 10.1016/j.pedn.2013.01.001. PMID: 23398894.

18) Brehaut JC, Kohen DE, Raina P, Walter SD, Russell DJ, Swinton M, et al. The health of primary caregivers of children with cerebral palsy: how does it compare with that of other Canadian caregivers? Pediatrics. 2004; 114(2): e182-91. doi: 10.1542/peds.114.2.e182. PMID: 15286255.

19) Breslau N, Staruch KS, Mortimer EA Jr. Psychological distress in mothers of disabled children. Am J Dis Child. 1982; 136(8): 682-6. doi: 10.1001/archpedi.1982.03970440026007. PMID: 6213143.

20) Grunewald K. Close the institutions for the intellectually disabled: Everyone can live in the open society. Available from: http://www.independentliving.org/docs7/grunewald2003.pdf

21) Chappell NL, Novak M. The role of support in alleviating stress among nursing assistants. Gerontologist. 1992; 32(3): 351-9. doi: 10.1093/geront/32.3.351. PMID: 1500000.

22) Van den Heuvel ET, De Witte LP, Schure LM, Sanderman R, Meyboom-de Jong B. Risk factors for burnout in caregivers of stroke patients, and possibilities for intervention. Clin Rehabi. 2001; 15(6): 669-77. doi: 10.1191/0269215501cr446oa. PMID: 11777097.

23) Demirhan E, İçağasığlu A, Eriman EÖ, Tezel CG, Baklacıoğlu HŞ, Haliloğlu S, et al. Burnout of primary caregivers of children with cerebral palsy. RISK. 2011; 66: 71.

24) Graneheim UH, Lundman B. Qualitative content analysis in nursing research: concepts, procedures and measures to achieve trustworthiness. Nurse educ today. 2004; 24(2): 105-12. doi: 10.1016/j.nedt.2003.10.001. PMID: 14769454.

25) Schwandt TA, Lincoln YS, Guba EG. Judging interpretations: But is it rigorous? Trustworthiness and authenticity in naturalistic evaluation. New directions for evaluation. 2007(114): 11-25. doi: 10.1002/ev.223.

26) Alarcon GM. A meta-analysis of burnout with job demands, resources, and attitudes. Journal of Vocational Behavior. 2011; 79(2): 549-62. doi: 10.1016/j.jvb.2011.03.007.

27) Horng Y-S, Hsieh S-F, Wu H-C, Feng C-T, Lin M-C. Work-related musculos keletal disorders of the workers in a Child Care Institution. Tw J Phys Med Rehabil. 2008; 36(1): 15-21.

28) Basaran A, Karadavut KI, Uneri SO, Balbaloglu O, Atasoy N. The effect of having a children with cerebral palsy on quality of life, burn-out, depression and anxiety scores: a comparative study. Eur J Phys Rehabil Med. 2013; 49(6): 815-22. PMID: 24285025.

29) Demerouti E, Bakker AB, Nachreiner F, Schaufeli WB. The job demands-resources model of burnout. J Appl psychol. 2001; 86(3): 499-512. doi: 10.1037/0021-9010.86.3.499. PMID: 11419809.

30) Vassos MV, Nankervis KL. Investigating the importance of various individual, interpersonal, organisational and demographic variables when predicting job burnout in disability support workers. Res Dev Disabi. 2012; 33(6): 1780-91. doi: 10.1016/j.ridd2012.04.016. PMID: 22699251.

31) Andersen EA. Working in long-term residential care: a qualitative metasummary encompassing roles, working environments, work satisfaction, and factors affecting recruitment and retention of nurse aides. Global journal of health science . 2009; 1(2).

32) Harrington C, Collier E, Schnelle JF, O' Meara J. Nursing indicators of quality in nursing homes. Journal of Gerontological Nursing. 2003; 29(10): 5-9. doi: 10.3928/0098-9134-20031001-04.

33) Bilgin S, Gozum S. Reducing burnout in mothers with an intellectually disabled child: an education programme. J Adv Nurs. 2009; 65(12): 2552-61. doi: 10.1111/j.1365-2648.2009.05163.x. PMID: 19941542.

34) Żołnierczyk-Zreda D. An intervention to reduce work-related burnout in teachers. Int J Occup Saf Ergon. 2005; 11(4): 423-30. doi: 10.1080/10803548.2005.11076661. PMID: 16329785. 